\title{
The graphene times
}

\author{
After 15 years of intensive academic research, graphene is getting ready to morph into a marketable technology.
}

A mid a wealth of remarkable carbonbased materials, no other stands out quite like graphene. In 2004, the famous report of the largely unexpected and counterintuitive possibility of isolating a stable single sheet of carbon had announced the dawn of the graphene era and the rise of two-dimensional (2D) materials ${ }^{1}$. Before too long, the one-of-a-kind mechanical and electronic properties of graphene were experimentally confirmed by a myriad of independent studies further spreading the promises of graphene for economic growth and innovation. Like so graphene became, as put by Andre Geim and Kostya Novoselov themselves, "a rising star on the horizon of materials science and condensed matter physics"2.

As the extensive scientific evidence kept piling up leaving no doubt of the importance of graphene in terms of fundamental physics, it simultaneously created unprecedentedly high expectations in the commercial realm. In the early days of graphene, researchers were speculating about the realization of a ballistic transistor that would end the dominance of silicon in electronics. Speaking of industrial applications shortly after the discovery, Geim predicted that "graphene could be ready in about 10 years" 3 . Indeed, by 2014 , material scientists were able to produce square metres of graphene and managed to build the first integrated circuit for wireless devices. The first roadmap was created to outline possible applications of graphene so as to predict whether it could become the next disruptive technology. However, while graphene academic research continued to flourish, even the most ardent advocates of graphene technology had to admit that it is still too early to expect 'the wonder material' to deliver on its many application promises. Andrea C. Ferrari, director of the Cambridge Graphene Centre, echoed the same sentiment in one of his early interviews by saying, "I'm never going to be able to replace the silicon transistor with graphene - not in my lifetime" ${ }^{\text {". But even }}$ though graphene was no longer perceived as a new silicon, there was an endless list of other applications to target in search for 'a killer'. Now, 15 years later, we are yet to see

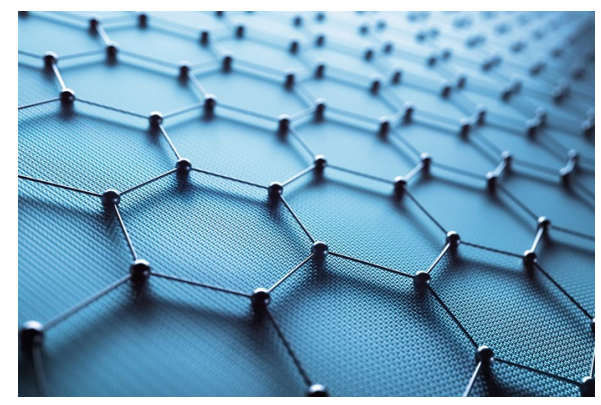

Credit: Science Photo Library/Alamy Stock Photo

whether graphene will ever be able to display its best qualities while making financial sense. Would it be in flexible displays, graphene-enhanced composites for airspace or buildings, batteries, photovoltaics or medical applications. Only time will tell.

Undeniably though, there has been remarkable progress in graphene research, quicker than that of any other material. On the account of the 15 years of incredible achievements and surprising discoveries in fundamental and applied physics, and the overall gigantic scientific effort put forward by the $2 \mathrm{D}$ community, graphene can afford the luxury of being slow to deliver on its technological potential. To appreciate the tremendous accomplishment of the field which has produced thousands of scientific papers every year - in this anniversary Focus issue we have decided to venture upon a very ambitious task of choosing the works that, in our humble opinion, have played a decisive role in the development of the field, proving to have long lasting effects on graphene research as a whole. We asked some of the most prominent experts in the field to validate our selection that is now presented in this issue's 'Graphene in the making' Feature for our readers to judge. Admittedly, it is impossible to encompass the 15 years of research in the list of 27 reports, but we hope that it can serve as a short narrative of how far the field has come since the 'fun Friday afternoon project'. Although the majority of the selected studies belong to the realm of fundamental physics, we haven't forgotten about some of the most valuable technologically relevant developments reporting graphene synthesis techniques. To further expand on this subject, in their Review, Wei Kong and colleagues discuss the progress enabled by more than a decade of research towards scalable production of graphene-based materials for their future commercialization and underline the key challenges, such as high cost and the lack of standardization, that currently hold back the implementation of graphene technologies.

As the field continues to mature, it is ever so important to establish a largescale partnership to improve the chances of commercially competitive graphene products. In a Feature in this issue, Silvia Milana discusses the prospects of the open call that has been recently launched by the Graphene Flagship, aimed at setting up an experimental pilot line for graphenebased electronics, optoelectronics and sensors. One of the main features of this initiative is to enable full compatibility with established complementary metal-oxidesemiconductor processes, which could potentially facilitate the shift of graphene technologies from academic laboratories to the industrial environment. Along the same lines, in two separate Comments, Terrance Barkan and Thomas Reiss provide their 'market pull' versus 'technology push' visions on the possible ways of bringing graphene to market. Despite the differences in their views, the authors agree that the tipping point for graphene commercialization is approaching, however, realistically, even 15 years of research and billions of euros of investment is still not enough to expect graphene to move from academic research into a marketable technology just yet. After all graphene is still in its teens, so let's wait for another five years to see.

Published online: 3 October 2019 https://doi.org/10.1038/s41565-019-0561-4

\section{References}

1. Novoselov, K. S. et al. Science 306, 666-669 (2004).

2. Geim, A. K. \& Novoselov, K. S. Nat. Mater. 6, 183-191 (2007).

3. Radical fabric is one atom thick. BBC News http://news.bbc. co.uk/1/hi/sci/tech/3944651.stm (2004).

4. Stoye, E. Graphene: looking beyond the hype. Scientific American https://www.scientificamerican.com/article/graphene-lookingbeyond-the-hype/ (2015). 